\title{
Using Technology Adoption Theories to Maximize the Uptake of E-learning in Medical Education
}

\author{
K. H. Vincent Lau ${ }^{1}$ (1) - David M. Greer ${ }^{1}$
}

Accepted: 24 February 2022 / Published online: 4 March 2022

(c) The Author(s) under exclusive licence to International Association of Medical Science Educators 2022

\begin{abstract}
Introduction While the use of e-learning tools in medical education is guided by robust literature on their design and evaluation, there is sparse literature on strategies that maximize their adoption among trainees.

Methods In this scoping review, we searched Web of Science for studies on technology adoption theories as applied to education, using a final censoring date of August 1, 2021.

Results Based on our findings, we identified three representative theories: (1) technology acceptance model, (2) technology adoption life cycle, and (3) domestication theory.

Discussion We describe these theories in detail, examine their prior applications, and propose specific uses within medical e-learning.
\end{abstract}

Keywords Technology $\cdot$ E-learning $\cdot$ Virtual learning $\cdot$ Flipped classroom

\section{Introduction}

The past decades have seen an expansion of e-learning in medical training, defined as internet-assisted learning that is generally distanced and asynchronous [1] such as computer-based teaching modules [2]. A 2015 survey of Internal Medicine residency program directors found that $72 \%$ of programs use at least one form of asynchronous e-learning [3]. E-learning has the advantages of convenience due to remote access and flexibility due to learner-set pace. It may also help bridge the digital divide in medical education by bringing high-quality content to learners in countries or regions where it is not locally available [4]. Its growing use was accelerated by the coronavirus disease-2019 (COVID19) pandemic, as health educators introduced teleconferencing for lectures, online practice questions, electronic procedural simulation [5], virtual learning platforms [6], and telemedicine training [7] into curricula. One study found that trainees who viewed technology-assisted learning in their program favorably had fewer concerns that their training was

K. H. Vincent Lau

vilau@bu.edu

1 Department of Neurology, Boston University School of Medicine, 72 East Concord Street, Neurology C-3, Boston, MA 02118, USA compromised by the pandemic [8]. Other studies conducted during the pandemic found that successful implementation of e-learning requires that educators focus on strategies to maximize learner engagement [9], minimize technical burden [10], and integrate tools conscientiously into existing learning environments [11].

There is a wealth of medical education literature on creating and evaluating e-learning tools such as video-based lectures [12] and computer-based teaching modules [13], as well as on broadly applicable design principles [2, 14, 15]. In contrast, there is little guidance on how to introduce them strategically to trainees to maximize acceptability, which is a missed opportunity as high-quality tools are helpful only if learners embrace them. The optimized uptake of technologybased tools is the subject of technology adoption theories prominent in the fields of sociotechnology and technology management $[16,17]$. Although they have been applied to education, they have not been systematically studied for their applicability to medical education.

\section{Methods}

We examined well-cited review articles on technology adoption theories in the fields of sociotechnology and technology management [18-20] to generate a comprehensive list of 


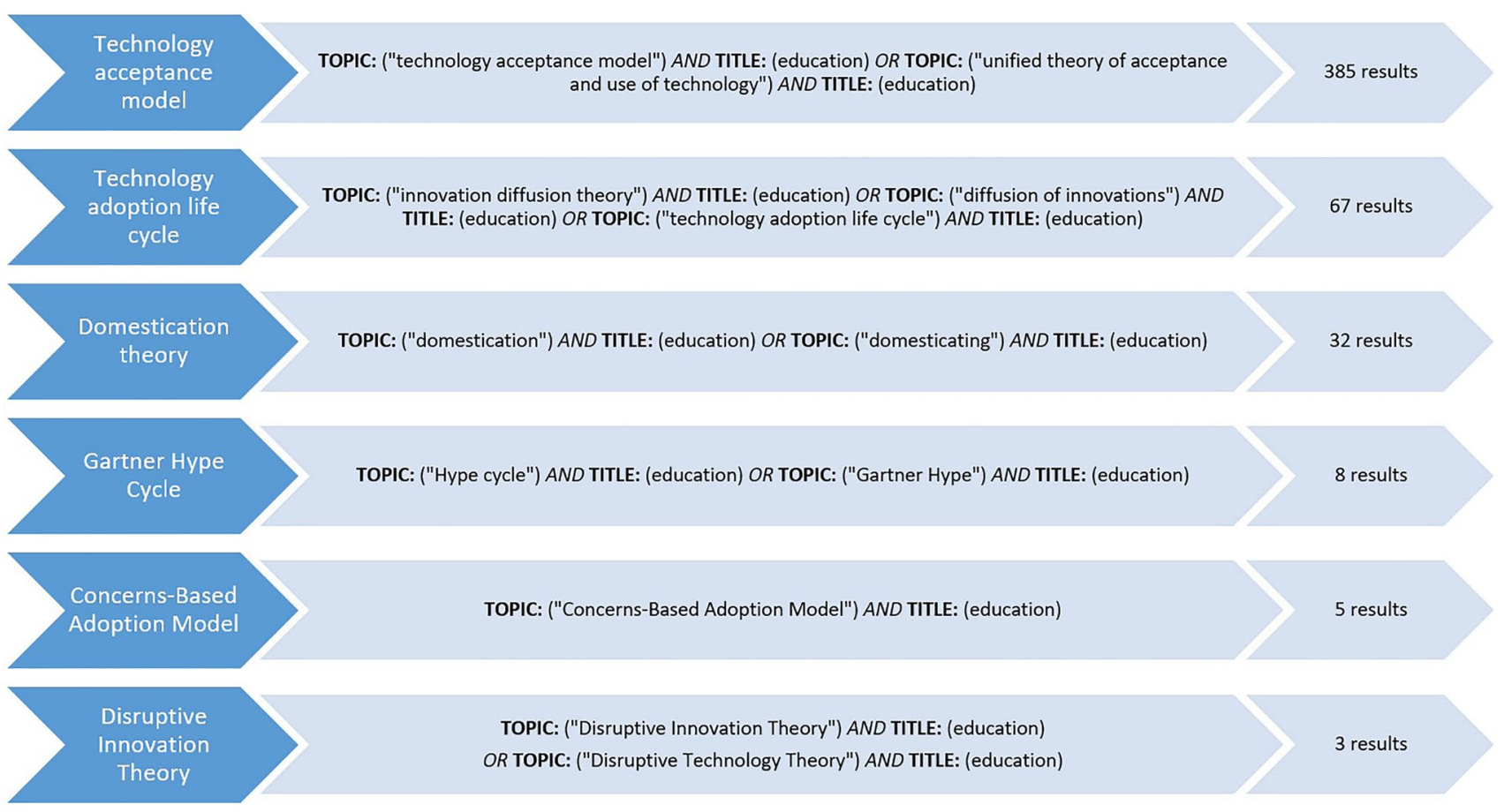

Fig. 1 Literature search methodology using the Web of Science Core Collection database, with a final censoring date of August 1, 2021

theories. We searched the Web of Science Core Collection database for these theories as applied to education using the search terms detailed in Fig. 1, with a final censoring date of August 1, 2021. Based on these results, we describe three representative theories in detail and explore their potential applications to e-learning in medical education.

\section{Results}

There were 385 publications on technology acceptance models (TAMs) and education, dominated in topic by learning management systems, massive open online courses (MOOCs), and other online courses. Less well-represented were podcasts, mobile learning, and blended learning environments. The versions of the theory most studied were classic TAM and unified theory of acceptance and use of technology (UTAUT) (details below). There were four studies specific to medical education on the topics of video capture technology for competency assessment in nurse practitioner education [21], online training for teaching cervical cancer detection for a broad audience of healthcare providers [22], virtual simulation in nursing education [23], and mobile learning in nursing education [24].

There were 67 publications on the technology adoption life cycle (TALC) and education, dominated in topic by MOOCs, e-textbooks, and blended learning environments. There were two studies based in medical education, one on the development of virtual communities in nursing education [25] and one on resources for learning anatomy on handheld electronic devices [26].

Although our search terms for the domestication theory and education yielded 32 publications, the vast majority were irrelevant due to the vagueness of the terms "domestication" and "domesticating"; however, one representative study investigated young people's adoption of technologies in formal and informal education settings [27]. There were eight publications on the Gardner Hype Cycle and education, five on the Concerns-Based Adoption Model and education, and three on the Disruptive Innovation Theory and education.

Based on these results, we identified three representative theories: TAM and TALC due to their relatively high representation in the literature and the domestication theory due to its complementary qualitative derivation against the quantitatively derived TAM. We describe each below, and summarize their principles and potential implementation strategies in Table 1.

\section{Technology Acceptance Models}

TAMs postulate that the final acceptability of a technology is a summation of its individual groups of attributes [28]. Originating in 1989 and revised in 2000 as TAM2, its next iteration termed the "unified theory of acceptance and use of technology" (UTAUT) collapsed a large set of attributes into four independent constructs [29], which has found strong 


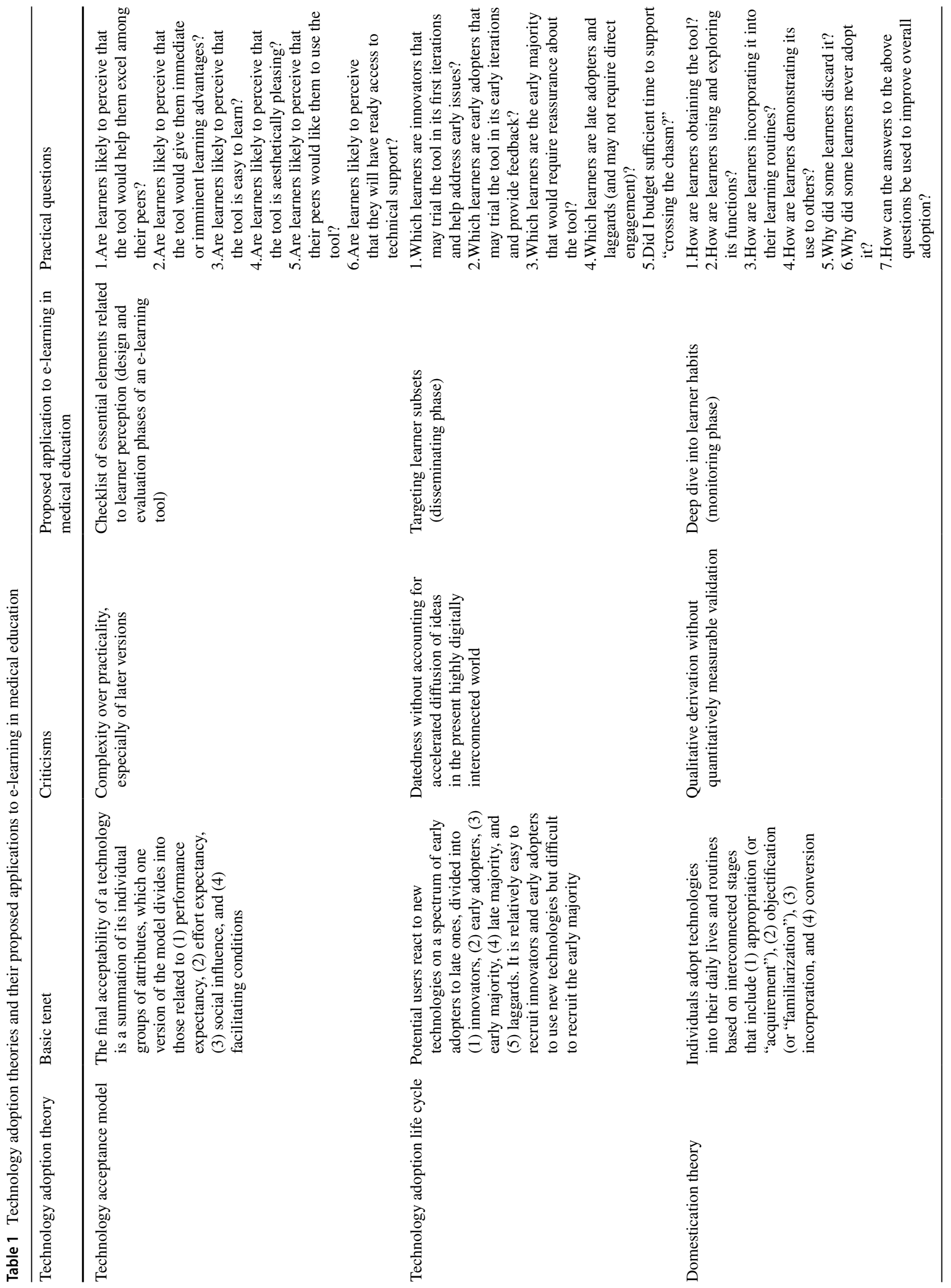


quantitative validity evidence. Although derived from studies on introducing technologies to the work environment, it has since been applied to a wide range of industries [30,31] including education $[32,33]$.

The UTAUT, which has been opined to represent an appropriate balance of sophistication and simplicity for most contexts, involves four constructs: (1) Performance expectancy refers to the degree to which users believe a new technology will help their job function, related to two contributing attributes: (a) relative advantage - perception that it will help its user stand out among peers and competitors - and (b) job-fit - perception that its advantage will be immediate or imminent. (2) Effort expectancy refers to usability, an important concept in the field of user-centered systems design [34] in which it is oftentimes divided into (a) cognitive aspects - whether the technology is efficacious and easy to learn - and (b) affective aspects whether it is enjoyable, aesthetically pleasing, or even emotionally fulfilling. (3) Social influence refers to the degree to which users perceive others believe they should use the technology, related to the TALC (see next section). (4) Facilitating conditions refers to the degree to which users believe they will have ready access to technical support [29]. While other extensions including UTAUT2 have subsequently emerged $[32,33]$, the field of TAM research has since been criticized for unnecessary complexity leading to limited applicability [35].

\section{Applying Technology Acceptance Models: Essential Elements Checklist}

Our literature search found that the majority of applications of TAMs used its constructs to evaluate different components of technology-assisted learning, with examples in medical education that include generic online learning [22] and mobile learning applications [24]. As such, the UTAUT may provide a useful checklist of essential elements related to learner perceptions to create or evaluate an e-learning tool in medical education, unrelated to its intrinsic andragogic value. It may be most applicable to the design and evaluation stages of an e-learning tool.

\section{Case Example}

An educator seeks to develop an online question bank for residents for self-study. Using the tenets of the four constructs, he advertises to residents that the question bank has content more clinically relevant than that found in commercial question banks (performance expectancy: relative advantage), with a complexity level appropriate to apply to routine work on the hospital wards or in the outpatient clinic (performance expectancy: job-fit). He works with a computer programmer to ensure that the user interface is both intuitive (effort expectancy: cognitive) and stylish (effort expectancy: affective). He plans to recruit specific learners to trial the question bank who would provide strong word-of-mouth promotion to increase its reputation (social influence; see next section). He ensures that learners have actual and perceived strong technical support by providing telephone contacts to troubleshoot issues in real-time and budgeting time to update the interface frequently in response to feedback (facilitating conditions).

In this case, failure to apply the UTAUT would be to neglect any one of the checklist elements, such as making the user interface seamless (effort expectancy: cognitive). Given that learners are quick to forfeit the use of any optional learning tool, the perception that it is technically cumbersome - even if the other elements in the checklist are optimized - may impede adoption.

\section{Technology Adoption Life Cycle}

The TALC, also known as the diffusion of innovation theory, characterizes how users react to new technologies on a spectrum of early adopters to late ones [36]. It places potential users into five groups along the spectrum, with varied profiles of risk acceptance, peer influence, and response to marketing techniques [37]. In 1991, an organizational theorist bolstered the model by introducing the concept of a metaphorical "chasm" between two specific groups. He argues that the chasm is responsible for the failure of adoption of many technologies, and is therefore the junction to which developers should devote the most time and resources during the dissemination phase of a new technology [38].

The TALC divides potential users into five groups, as shown in Fig. 2. Innovators have high comfort with technology and high risk tolerance. They are interested in technology for its own sake, representing the easiest market. Early adopters (sometimes termed "enthusiasts") are similarly

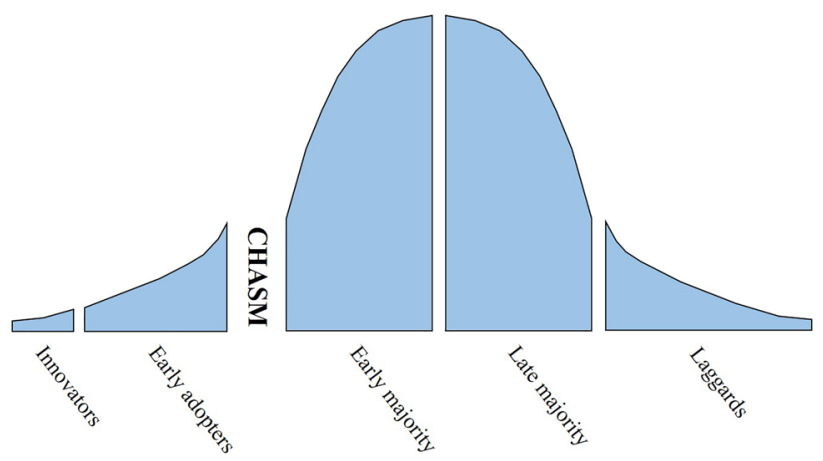

Fig. 2 Technology adoption life cycle ( Adapted from Moore [38] ). This model divides potential users of a new technology on a spectrum of early adopters to late ones. The "chasm" corresponds to the difficulty recruiting the "early majority" to use the technology relative to the ease with which "innovators" and "early adopters" may be recruited 
comfortable with technology and have at least moderate to high risk tolerance. They consider technology a way to improve their performance among their peers. They respond readily to influence by innovators, whom they see as leaders that can scrutinize a technological product for them. The early majority (sometimes termed "pragmatists") are risk adverse and suspicious of new technologies. They are immune to influence from innovators and early adopters, whom they view as impractical. Instead, they respond to marketing techniques specific to their needs. They only trust technologies that are complete, helpful but not novel for novelty's sake, and well-accepted by others in their own group, i.e., other "pragmatists." The tendency for the early majority to only be influenced by each other as opposed to members of the other groups makes engaging them challenging for developers. As such, "crossing the chasm" corresponds to the transition from recruiting early adopters (relatively easy) to recruiting the early majority (relatively difficult) [38]. Finally, late adopters require little directed marketing effort - they will adopt a new technology when it is fully accepted by the first three groups, while laggards may either follow suit or never adopt it [36]. Criticisms of the TALC focus on its datedness; it does not take into account the rapid and disruptive pace at which modern technologies spread in today's highly digitally interconnected world, making traditional models of diffusion less applicable [39].

\section{Applying the Technology Adoption Life Cycle: Targeting Learner Subsets}

Our literature search found that the TALC was most frequently used for educational technologies that were considered optional, such that they rely heavily on word-of-mouth. An example is the use of mobile-based resources to learn anatomy [26], which an educator may make available to learners without mandating its use. Medical educators may use the TALC to target learner groups at different times and in distinct ways to maximize overall adoption of an e-learning tool, most relevant during its dissemination phase.

\section{Case Example}

In response to concerns that remote lectures are depersonalizing, an educator develops a web-based application that helps learners prepare for scheduled didactics using elements of the flipped classroom model [40, 41]. The application allows learners to complete multiple-choice questions on the didactic topic written by the lecturer as "prework" and to contribute to a "wiki" of notes such as mnemonic devices related to the topic. The educator makes the use of the application optional given residents' heterogeneous schedules and competing responsibilities, applying the TALC to maximize engagement.

The educator loosely categorizes residents into the five groups based on their comfort with technology. She first targets one or two innovators - residents who are not only comfortable with technology but also enjoy it for its own sake - and asks them to trial early prototypes and provide detailed feedback on its design. Next, she approaches a few early adopters - residents who are comfortable with technology and may view new learning tools as a means to stand out among their peers, asking them to trial the completed application and provide feedback. Next, the educator "crosses the chasm" by targeting the "early majority" residents who are moderately comfortable with technology but simultaneously suspicious of new modes of learning, somewhat easily deterred by errors and inefficiencies. She presents the application at a residency meeting, letting residents know that it is in its near-final form, that it is helpful for consolidating knowledge, and that it weaves seamlessly into the current didactics system. She de-emphasizes its novel components, aware that the early majority are more interested in the practical rather than technologically innovative aspects of the tool. She also budgets time to make rapid revisions based on feedback. At this point, the die has been cast whether the application will be successfully adopted by the residency program. If the chasm is crossed, the remainder of residents who have little comfort with technology is likely to later adopt the application as it becomes the new "norm," while a few may never embrace it.

Failure to apply the TALC in this case corresponds with a break in any part of the chain, in particular the "chasm." For example, adoption may fail if the educator introduces the application too early to the majority of residents before it can garner a strong reputation among innovators and early adopters, and before early technical issues are addressed.

\section{Domestication Theory}

While the TALC focuses on groups of people, the domestication theory focuses on individuals. Originally developed by European researchers, early iterations characterized how individual households adopt new forms of media such as television sets and computers [41, 42]. Since then, it has been used to describe large-scale technological movements, such as how the social networking service Facebook became deeply integrated into the lives of college students in its early years [42] or how smartphone applications have become ubiquitous in Americans' lives [43]. The theory differs greatly from the quantitatively derived TAM by focusing on the qualitative, social aspects of adoption including how a technology fits into a person's routines and habits. As such, domestication studies rely heavily on qualitative methods such as interviews and direct observations [44]. 
The domestication theory classifies technology adoption into stages but emphasizes their non-linear and interconnected relationships [45]. These are appropriation - obtaining the technology, objectification - using it and exploring its functions, incorporation - placing it into daily routines - and conversion - displaying its use to others. Related to these stages are two additional concepts of de-domestication - the discarding of a technology after it had been embedded into a user's routine - and non-use - the rejection of a technology despite acceptance by the vast peer majority $[45,46]$. The theory has been criticized for its lack of measurable empirical validation as it was derived primarily via detailed case studies, but this weakness may be germane to the qualitatively derived nature of the model [44].

\section{Applying the Domestication Theory: Deep Dive into Learner Habits}

Our literature search found that the domestication theory has not been well-utilized in education, although one relevant article did examine young people's domestication of educational technologies and "how individual learning technologies fit into wider socio-technical systems and networks [27]." Based on the origin of the theory, it may be most applicable to e-learning tools designed specifically for home use, such as commercial e-textbooks. While data analytics that monitor usage patterns of such tools may capture helpful information such as log-in frequencies or number of page visits [46], this information is actionable only when complemented by a deep dive into learners' habits, routines, and preferences during the evaluation phase of an e-learning tool.

\section{Case Example}

An educator purchases a commercial e-textbook for residents' use for home study. After the first month, she reviews the analytics data to find that less than half of the residents used the virtual textbook consistently. An electronic survey finds reasons for low use that include "not enough time," "technical difficulties," and "n/a." In response, she holds short, informal interviews with resident groups. Her specific questions include how and when the program is installed onto personal laptops or other devices (appropriation), how learners are able to explore its functions (objectification), when it is used - for example the reading of a specific chapter in preparation for a scheduled didactic or hospital rotation (incorporation), and whether its use is influenced by peers or faculty members who recommend particularly useful content (conversion). She also targets specific learners to understand why some early users stopped using the tool (de-domestication) and why others never use it (non-use).
Based on these answers, she learns that residents greatly value reviewing some chapters to prepare for specific rotations and that infrequent users find the application slows at a specific loading point. In response, she creates a list of suggested chapters to review during individual rotations and provides feedback to the company regarding the technical issue.

Failure to apply the domestication theory in this case would be to assume that poor adoption is due to its lack of quality or fit with the curriculum. Poor specificity in survey answers may lead an educator to prematurely abandon an e-learning tool that would have benefited trainees.

\section{Discussion}

This scoping review identified key technology adoption theories that may have highest relevance to e-learning in medical education. Although the TAM has been better represented in the literature than the others, their application as used individually or in combination should be selected based on the appropriate contexts as described, for example the domestication theory for tools designed for home use. In addition, there are a few important nuances to their practical implementation. First, maximizing the adoption of an e-learning tool should not take precedence over evaluating its andragogic advantages or fit within a curriculum. Conversely, a frequently used e-learning tool does not guarantee its andragogic value, as learners may engage for the wrong reasons, such as to appease the educator or for entertainment. As such, educators must rigorously evaluate both the intrinsic value of an e-learning tool and its adoptability.

Second, the rigor with which these models are applied to e-learning tools should be proportional to the risk of failure of adoption. For example, tools that are offered by educators for optional use or intended solely for home use may have higher risk and therefore warrant greater attention on their acceptability. Technology adoption theories may also be more important in certain settings, for example in graduate medical education in which a higher proportion of e-learning tools are asynchronous and non-mandatory compared to in undergraduate medical education. Given the effort and expertise required from educators to apply these theories, the incorporation of basic technology adoption theories into faculty development would be an important area of future research.

Third and more broadly, when considering the use of e-learning in medical education, educators should acknowledge both the potential drawbacks of individual tools [2] and the larger-scale unintended consequences of technology-assisted learning, the latter including distraction and dependency [47] and inappropriate incorporation of technologies based solely on their novelty rather than andragogic 
advantages, a concept sometimes termed "edutainment [48]."

Our work has several limitations, first that we attempted to capture a bird's eye view of the narrow field of technology adoption theories as applied to education. Although our literature search generated a sufficient sample to characterize the field, we could have improved sampling accuracy by expanding the search to other databases such as Scopus. Second, we applied the macroscopic principles of technology adoption theories to the microscopic setting of e-learning in medical education, although we argue that the tenets of these theories translate well to our context. Finally, as germane to literature searches with imperfect search terms, we reviewed a subset of articles irrelevant to the topic that inflated the number of articles per theory, which we have addressed above.

\section{Conclusions}

E-learning tools have gained an increasingly prominent role in medical education in recent decades, a phenomenon accelerated by the COVID-19 pandemic. To maximize the acceptability of high-quality e-learning tools and afford trainees their intended andragogic benefits, modern medical educators may apply basic technology adoption theories to better engage learners in the digital age. Although this scoping review has incorporated many robust studies examining their use, further exploration of both the applications of individual theories and their combination may yield bestpractice recommendations on their application to medical education.

Author Contribution All authors meet the journal criteria for authorship.

Availability of Data and Material Data is available upon reasonable request.

\section{Declarations}

\section{Ethics Approval N/A.}

Consent to Participate N/A.

Consent for Publication N/A.

Conflict of Interest The authors declare no competing interests.

\section{References}

1. Ruiz JG, Mintzer MJ, Leipzig RM. The impact of e-learning in medical education. Acad Med. 2006;81(3):207-12.
2. Lau KHV, Lakhan SE, Achike F. New media, technology and neurology education. Semin Neurol. 2018;38(4):457-64.

3. Wittich CM, et al. E-learning in graduate medical education: survey of residency program directors. BMC Med Educ. 2017;17(1):114.

4. Murali M. Tackling global medical education inequality through e-learning. Med Educ. 2017;51(5):556-7.

5. Chick RC, et al. Using technology to maintain the education of residents during the COVID-19 pandemic. J Surg Educ. 2020;77(4):729-32.

6. Almarzooq ZI, Lopes M, Kochar A. Virtual learning during the COVID-19 pandemic: a disruptive technology in graduate medical education. J Am Coll Cardiol. 2020;75(20):2635-8.

7. Remtulla R. The present and future applications of technology in adapting medical education amidst the COVID-19 pandemic. JMIR Med Educ. 2020.

8. Guo T, et al. Impact of the COVID-19 pandemic on Otolaryngology trainee education. 2020.

9. Rajeh MT, et al. Students' satisfaction and continued intention toward e-learning: a theory-based study. Med Educ Online. 2021;26(1):1961348.

10. Padhi KS, et al. The perspectives of educators and learners on e-learning: a cross-sectional descriptive study in a medical school. Adv Med Educ Pract. 2021;12:1059-66.

11. Shabila NP, et al. Exploring the perspectives of medical students on application of e-learning in medical education during the COVID-19 pandemic. Work. 2021;70(3):751-62.

12. Dong C, Goh PS. Twelve tips for the effective use of videos in medical education. Med Teach. 2015;37(2):140-5.

13. Lau KH. Computer-based teaching module design: principles derived from learning theories. Med Educ. 2014;48(3):247-54.

14. Kaplovitch E, et al. Cost-efficient medical education: an innovative approach to creating educational products. J Grad Med Educ. 2019;11(6):713-6.

15. Sandars J, Lafferty N. Twelve tips on usability testing to develop effective e-learning in medical education. Med Teach. 2010;32(12):956-60.

16. Nagarajan K. A brief course on technology management. Daryaganj, New Delhi, India: Daryaganj. New Delhi, India: New Age International P Ltd., Publishers. 2015.

17. Akhilesh KB. Emerging dimensions of technology management. India. India: Springer; 2013.

18. Jandrić P. Diffusionist model of adoption of digital learning. Encyclopedia of educational philosophy and theory, M.A. Peters, Editor, Springer Singapore: Singapore. 2017:561-6.

19. Straub ET. Understanding technology adoption: theory and future directions for informal learning. Rev Educ Res. 2009;79(2):625-49.

20. Hillmer U. Existing theories considering technology adoption. 2009:9-28.

21. Strand $\mathrm{H}$, et al. A pilot project in distance education: nurse practitioner students' experience of personal video capture technology as an assessment method of clinical skills. Nurse Educ Today. 2013;33(3):253-7.

22. Muljo HH, Perbangsa AS, Pardamean B. Assessment of online learning application for health education. Int J Onl Biomed Eng. 2019;15(12):69-80.

23. Padilha JM, et al. Clinical virtual simulation in nursing education. Clin Simul Nurs. 2018;15:13-8.

24. Buabeng-Andoh C. New technology in health education: nursing students' application of mobile technology in the classroom in Ghana. Interactive Technology and Smart Education. 2018;15(1):46-58.

25. Giddens JF, Walsh M. Collaborating across the pond: the diffusion of virtual communities for nursing education. J Nurs Educ. 2010;49(8):449-54. 
26. Trelease RB. Diffusion of innovations for education: anatomy resources for the iPod. FASEB J. 2006;20(5):A847.

27. Selwyn N. Making sense of young people, education and digital technology: the role of sociological theory. Oxf Rev Educ. 2012;38(1):81-96.

28. Davis FD. Perceived usefulness, perceived ease of use, and user acceptance of information technology. MIS Q. 1989;13(3):319-40.

29. Venkatesh $\mathrm{V}$, et al. User acceptance of information technology: toward a unified view. MIS Q. 2003;27(3):425-78.

30. Magsamen-Conrad K, et al. Bridging the divide: using UTAUT to predict multigenerational tablet adoption practices. Comput Hum Behav. 2015;50:186-96.

31. Bixter MT, et al. Understanding the use and non-use of social communication technologies by older adults: a qualitative test and extension of the UTAUT model. Gerontechnology. 2019;18(2):70-88.

32. Šumak B, Šorgo A. The acceptance and use of interactive whiteboards among teachers: differences in UTAUT determinants between pre- and post-adopters. Comput Hum Behav. 2016;64:602-20.

33. Chao CM. Factors determining the behavioral intention to use mobile learning: an application and extension of the UTAUT model. Front Psychol. 2019;10:1652.

34. Göransson B, Gulliksen J, Boivie I. The usability design process — integrating user-centered systems design in the software development process. Software Process: Improvement and Practice. 2003;8(2):111-31.

35. Bagozzi R. The legacy of the technology acceptance model and a proposal for a paradigm shift. J AIS. 2007;8.

36. Rogers EM. Diffusion of innovations. New York: The Free Press; 1962.

37. Meade PT, Rabelo L. The technology adoption life cycle attractor: understanding the dynamics of high-tech markets. Technol Forecast Soc Chang. 2004;71(7):667-84.
38. Moore GA. Crossing the chasm: marketing and selling high-tech products to mainstream customers. New York. NY: Harper Business Essentials; 1991.

39. Pace S. Looking at innovation through CCT glasses: consumer culture theory and Google glass innovation. J Innov Manage. 2013;1(1):38-54.

40. Hew KF, Lo CK. Flipped classroom improves student learning in health professions education: a meta-analysis. BMC Med Educ. 2018;18(1):38.

41. Sandrone $\mathrm{S}$, et al. Education research: flipped classroom in neurology: principles, practices, and perspectives. Neurology. 2019;93(1):e106-11.

42. Watulak SL, Whitfield D. Examining college students' uptake of Facebook through the lens of domestication theory. E-Learning and Digital Media. 2016;13(5-6):179-95.

43. de Reuver M, Nikou S, Bouwman H. Domestication of smartphones and mobile applications: a quantitative mixed-method study. Mob Med Commun. 2016;4(3):347-70.

44. Berker T, et al. Domestication of media and technology, Maidenhead: Maidenhead : Open University Press. 2006.

45. Haddon L. Roger Silverstone's legacies: domestication. New Media Soc. 2007;9(1):25-32.

46. Lau KHV, et al. Using learning analytics to evaluate a video-based lecture series. Med Teach. 2018;40(1):91-8.

47. Bullock A, Webb K. Technology in postgraduate medical education: a dynamic influence on learning?. Postgrad Med J. 2015;91(1081):646-50.

48. De Leeuw RA, et al. Quality specifications in postgraduate medical e-learning: an integrative literature review leading to a postgraduate medical e-learning model. BMC Med Educ. 2016;16:168.

Publisher's Note Springer Nature remains neutral with regard to jurisdictional claims in published maps and institutional affiliations. 